\title{
Computational Design of Novel, Radiation Resistant Fusion Materials
}

\author{
A. Kubota, M.J. Caturla, B.D. Wirth, J. Latkowski \\ February 1, 2003
}

U.S. Department of Energy

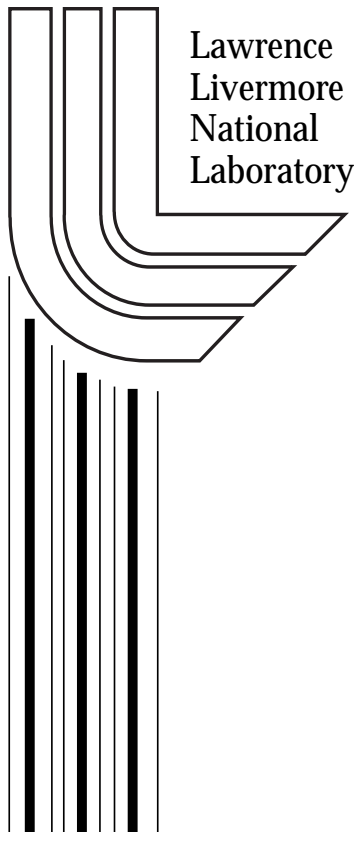




\section{DISCLAIMER}

This document was prepared as an account of work sponsored by an agency of the United States Government. Neither the United States Government nor the University of California nor any of their employees, makes any warranty, express or implied, or assumes any legal liability or responsibility for the accuracy, completeness, or usefulness of any information, apparatus, product, or process disclosed, or represents that its use would not infringe privately owned rights. Reference herein to any specific commercial product, process, or service by trade name, trademark, manufacturer, or otherwise, does not necessarily constitute or imply its endorsement, recommendation, or favoring by the United States Government or the University of California. The views and opinions of authors expressed herein do not necessarily state or reflect those of the United States Government or the University of California, and shall not be used for advertising or product endorsement purposes.

This work was performed under the auspices of the U. S. Department of Energy by the University of California, Lawrence Livermore National Laboratory under Contract No. W-7405-Eng-48.

This report has been reproduced directly from the best available copy.

Available electronically at http://www.doc.gov/bridge

Available for a processing fee to U.S. Department of Energy

And its contractors in paper from

U.S. Department of Energy

Office of Scientific and Technical Information

P.O. Box 62

Oak Ridge, TN 37831-0062

Telephone: (865) 576-8401

Facsimile: (865) 576-5728

E-mail: reports@adonis.osti.gov

Available for the sale to the public from

U.S. Department of Commerce

National Technical Information Service

5285 Port Royal Road

Springfield, VA 22161

Telephone: (800) 553-6847

Facsimile: (703) 605-6900

E-mail: orders@ntis.fedworld.gov

Online ordering: http://www.ntis.gov/ordering.htm

OR

Lawrence Livermore National Laboratory

Technical Information Department's Digital Library

http://www.llnl.gov/tid/Library.html 


\section{Computational Design of Novel, Radiation Resistant Fusion Materials}

Alison Kubota, Maria-Jose Caturla, Brian D. Wirth and Jeffery Latkowski

Lawrence Livermore National Laboratory

\section{Introduction}

The promise of fusion as a viable $21^{\text {st }}$ century energy source requires the development of advanced structural (MFE and IFE) and optical (IFE) materials that are capable of withstanding the harsh radiation environment that leads to the degradation of physical and mechanical properties. Materials in fusion environments must be able to handle 14 $\mathrm{MeV}$ neutrons produced from Deuterium-Tritium nuclear reactions, as well as the insoluble $\mathrm{He}$ and reactive $\mathrm{H}$ gases that lead to swelling and embrittlement. Additionally, with the requirement of very high thermal loads makes the development of new advanced materials a formidable challenge.

The scope of this study was to determine the feasibility of using atomistic simulations to predict the radiation response of novel materials engineered with potentially self-healing properties to survive in radiation environments over very long time-scales. The class of materials that shows promise is what is called a nanocrystalline material. Nanocrystalline materials are defined as those having very fine grains on the order of several to tens of nanometers in size, and consequently very high grain-boundary to volume ratio. Experimental observations [1] suggests that these grain-boundary networks can act as sinks for defects and hence promote self-repair.

\section{Technical Accomplishments}

We performed classical molecular dynamics simulations to understand the response of nanocrystalline materials to radiation damage. During the FY2002, we performed largescale molecular dynamics simulations to understand the behavior of defect "debris fields" produced by energetic recoil atoms with up to $20 \mathrm{keV}$ of kinetic energy, near grain boundaries.

The embedded atom potentials (EAM) [2] for $\mathrm{Cu}$ were used to define the interactions between particles. A computational supercell representing nanocrystalline grains with high-angle grain boundaries was produced using a Voronoi polyhedra algorithm. The computational supercell was constructed to a cube approximately $23 \mathrm{~nm}$ on each side, with grains averaging of $10 \mathrm{~nm}$ across. This initial condition configuration containing over one million atoms was then equilibrated for over 200 psec by coupling to a $300 \mathrm{~K}$ thermostat and a Parinello-Rahman[3] algorithm.

Damage cascades were produced by introducing a large velocity component to a single atom. $10 \mathrm{keV}$ and $20 \mathrm{keV}$ primary recoil energies were chosen to allow for a significant and meaningful quantity of cascade debris that will then interact with the grain boundaries over the following 10 s to 100 s of picoseconds. We performed the following four cascade simulations: (1) $10 \mathrm{keV}$ recoil in single-crystal $\mathrm{Cu}$ for comparison with nanocrystalline results, (2) $10 \mathrm{keV}$ recoil with cascade debris centered in the middle of a grain, (3) $10 \mathrm{keV}$ recoil with cascade debris produced across a grain boundary, and (4) 20 
$\mathrm{keV}$ recoil with a large debris field. We discuss the results of each cascade trajectory below.

\section{$10 \mathrm{keV}$ recoil in single-crystal $\mathrm{Cu}$}

We performed a cascade simulation in single crystal $\mathrm{Cu}$ as a baseline simulation to show the expected behavior of defects produced far from grain boundaries. Figure 1 shows the simulation cell approximately 167 psec after the cascade initiation. Shown is a splitrepresentation in which all atoms below a particular plane are shown while only certain atoms above the same plane are shown. The white, green and blue colorations represent atoms with locally face-centered cubic (fcc), hexagonal close-packed (hcp) and disordered local structure, respectively. This representation, called "common neighbor analysis[4]," is a method used to differentiate atoms based on local topological rules that also differentiate different crystal structures. Thus, the majority of atoms have are fcc, while the colored spheres signify lingering stable defects. Further analysis shows the formation of 30 stable Frenkel pairs in this calculation, with interstitials generally surrounding a vacancy core.

\section{$10 \mathrm{keV}$ in $\mathrm{Cu}$ nanocrystal with cascade debris centered in the middle of a grain}

Figure 2(a-d) shows the same split-representation of a nanocrystal exposed to a $10 \mathrm{keV}$ recoil. Figure 2(a) shows the grain boundaries represented by the localized blue and green hcp and disordered atoms. Note the variations in the contributions of hcp and disordered atoms (blue and green) at different grain-boundary planes. Figure 2(b) shows the instantaneous cascade structure and debris at 1.5 psec after the cascade inception. Also notice the light-blue dendritic tree-like structure surrounded by the mass of disordered blue atoms. This dendritic structure represents the "cascade-track." The cascade track is defined as the collection of paths of atoms with more than $5 \mathrm{eV}$ of kinetic energy. This cascade track was shown to produce a defect debris field that was localized within the central grain, as shown in Figure 2(c). Figure 2(c) is a snapshot of the simulation cell at 14 psec after recoil inception. Finally, Figure 2(d) shows the stable structure of defects at 83 psec. Detailed analysis has shown most interstitial defects by this time to have migrated to and absorbed into the grain boundaries, with the few remaining vacancy defects remaining within the grain. These vacancies can be expected to also eventually migrate to the grain boundaries over time-scales much longer than feasible using classical molecular dynamics simulations.

\section{$10 \mathrm{keV}$ in $\mathrm{Cu}$ nanocrystal with cascade debris centered near a grain boundary}

In this simulation we produced a $10 \mathrm{keV}$ cascade debris field very near a grain boundary. Figure 3(a) shows the instantaneous cascade debris and cascade track structures at 1 psec. Qualitatively, this femtosecond time-scale transient cascade structure shows few meaningful differences to those in the previous two simulations. However, significant differences are evident in Figure 3(b) that shows the lattice at $83 \mathrm{psec}$, long after the cascade has thermalized. The first feature of Figure 3(b) is the "warping" of the grain boundary closer towards the debris field, suggesting that grain boundary migration and 
grain growth may be significant issues to fusion material selection and design, even after single cascade events. The second feature of Figure 3(b) is the collection of green hcp atoms that have coalesced along a (111) crystallographic plane near the debris field. The formation of these faulted structures can in general lead to the hinderance of dislocation motion and result in material hardening, another issue important to fusion material design.

\section{$20 \mathrm{keV}$ in $\mathrm{Cu}$ nanocrystal}

In our fourth simulation, we produced a cascade debris field with a $20 \mathrm{keV}$ recoil. Figure 4(a) shows the cascade debris and track after 1.2 psec. In this particular simulation, we observed several very interesting and unique processes that were unexpected and are poorly understood. Figure 4(b) shows the nanocrystal at 19 psec, very soon after the cascade has thermalized. The green hcp structure that extends up from the debris field is a dislocation that appears to extend up to a grain boundary, although only for several picoseconds. Figure 4(c) shows the nanocrystal at 24.7 psec, immediately as the partial dislocation and the cascade debris field has collapsed into a number of truncated stacking-fault tetrahedras (SFTs). This SFT complex, is then observed to gradually flatten out into a single faulted hep structure as shown in Figure 4(d) after 227 psec.

\section{Summary}

During the FY2002, we have successfully used large-scale molecular dynamics simulations to demonstrate some self-healing properties of nanocrystalline $\mathrm{Cu}$ for low doses that correspond to our single-recoil cascade simulations. The migration to and absorption of interstitial defects at the grain boundaries are indications that high-grainboundary-density materials show promise as damage-resistant fusion materials. In addition, these molecular dynamics simulations have opened the doors to a vast wealth of new scientific insight regarding the poorly understood interactions of energetic cascades and resultant debris fields with grain boundaries and other extended defects that, to our knowledge, have not been studied for.

This work was performed under the auspices of the U. S. Department of Energy by the University of California, Lawrence Livermore National Laboratory under Contract No. W-7405-Eng-48 


\section{References:}

[1] M. A. Shaikh, Jour. Nuclear Mat., 187 (1992) 303

[2] S. M. Foiles, Phys. Rev. B., 32 (1985) 7685

[3] M. Parrinello and A. Rahman, J. Appl. Phys. 52 (1981) 7182

[4] A. S. Clarke and H. Jonsson, Phys. Rev. E., 47 (1993) 3975 


\section{Figures:}

Figure 1: Split-representation of a $23 \mathrm{~nm} \times 23 \mathrm{~nm} \times 23 \mathrm{~nm}$ supercell of pristine singlecrystal copper at $167 \mathrm{psec}$ after the initiation of a $10 \mathrm{keV}$ recoil cascade. The white, green and blue colorations correspond to fcc, hcp and disordered atoms. The coloration schemes are explained in detail in the text. 30 stable frenkel pairs were produced in total.

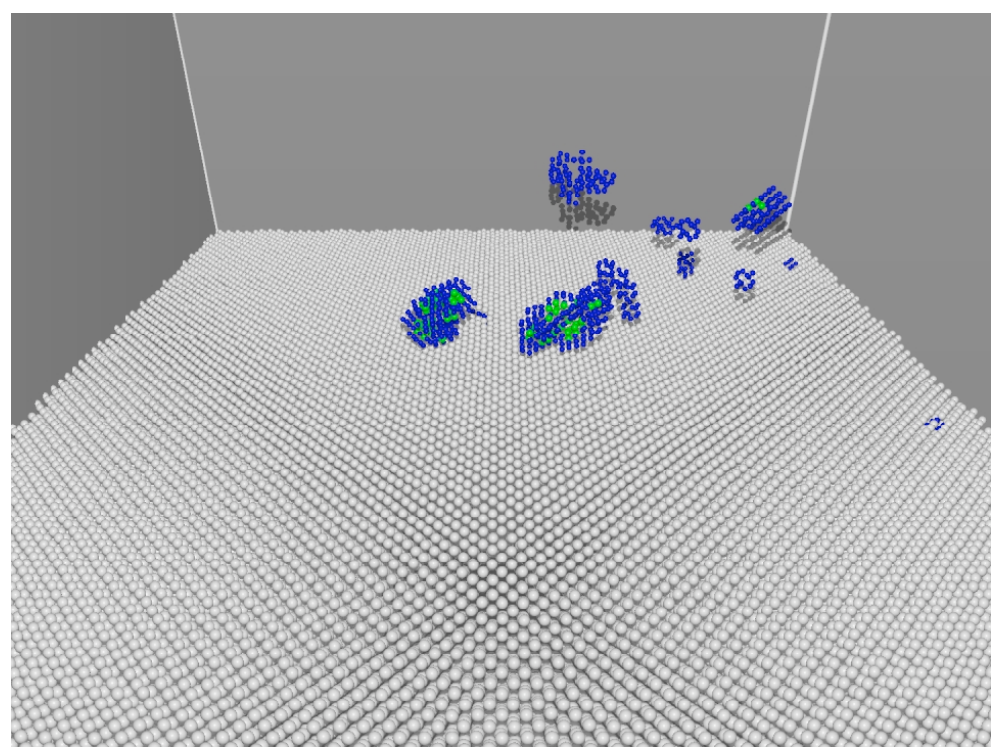


Figure 2(a-b): Split-representations of the $\mathrm{Cu}$ nanocrystal before and after $10 \mathrm{keV}$ recoil initiation. Figure 2(a) shows the structure prior to cascade initiation, with the hcp (green) and disordered (blue) atoms associated with the grain boundaries. Figure 2(b) shows the instantaneous cascade structure (blue mass) and cascade track (light-blue to orange dendritic feature) associated with the path of atoms that have energies larger than $5 \mathrm{eV}$. (See text for details). Figure 2(b) is at $1.5 \mathrm{psec}$ after cascade initiation.

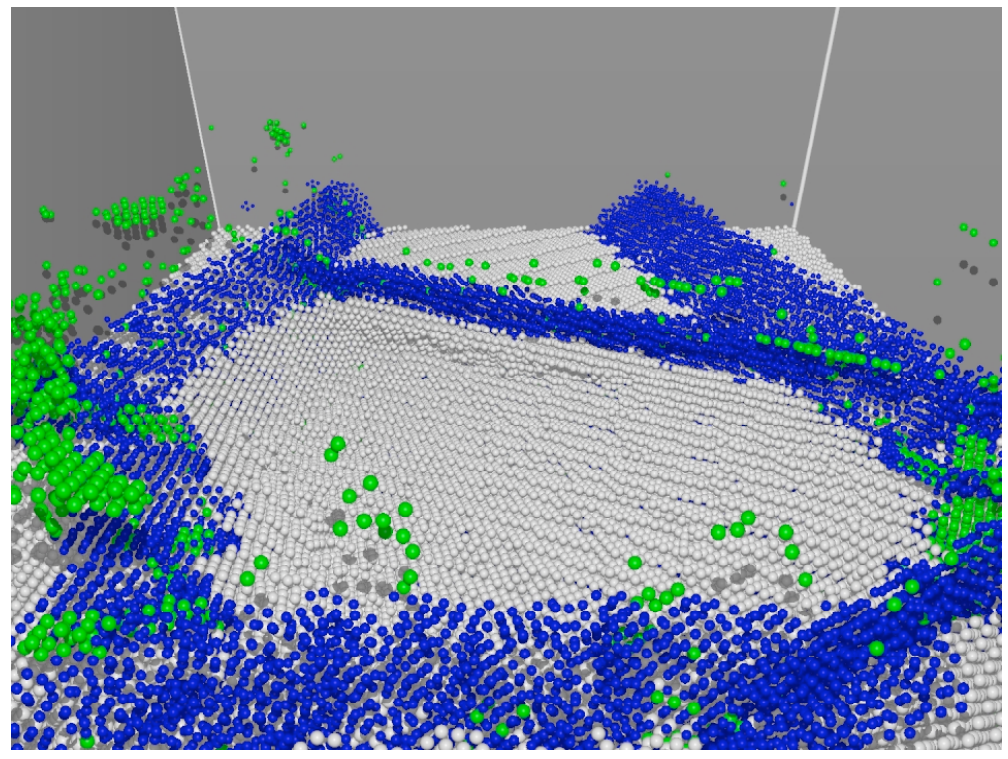

(a)

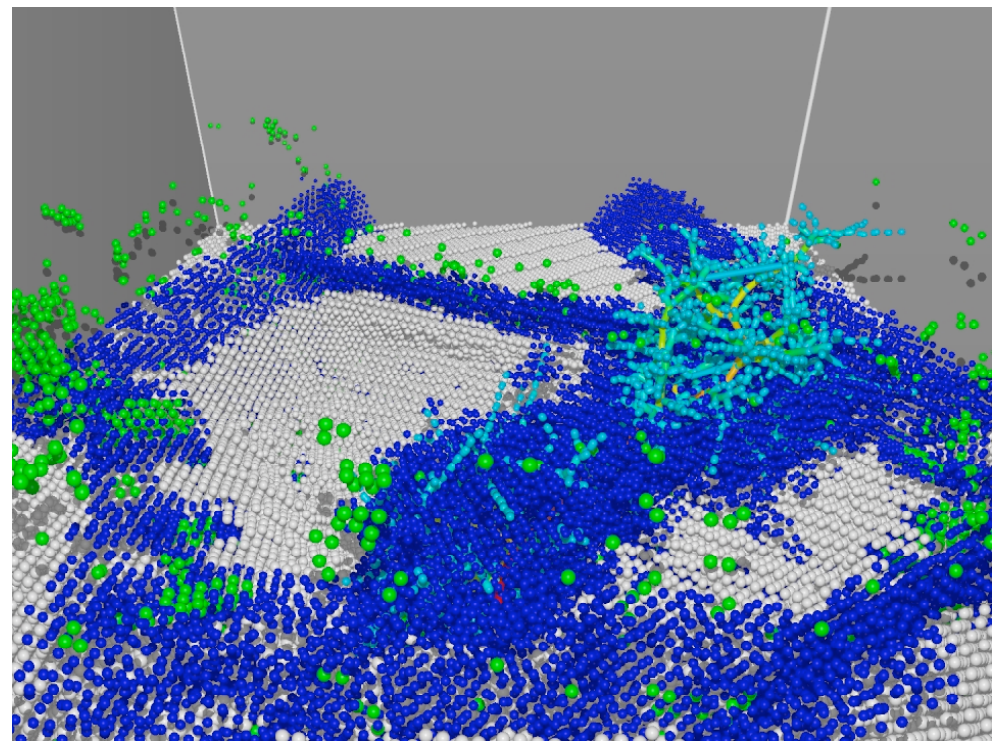

(b) 
Figure 2(c-d): Split-representations of the $\mathrm{Cu}$ nanocrystal after $10 \mathrm{keV}$ recoil initiation. Figure 2(c) shows the structure at $14 \mathrm{psec}$ after initiation. Figure 2(d) shows the significantly reduced cascade debris after $83 \mathrm{psec}$. (See text for details).

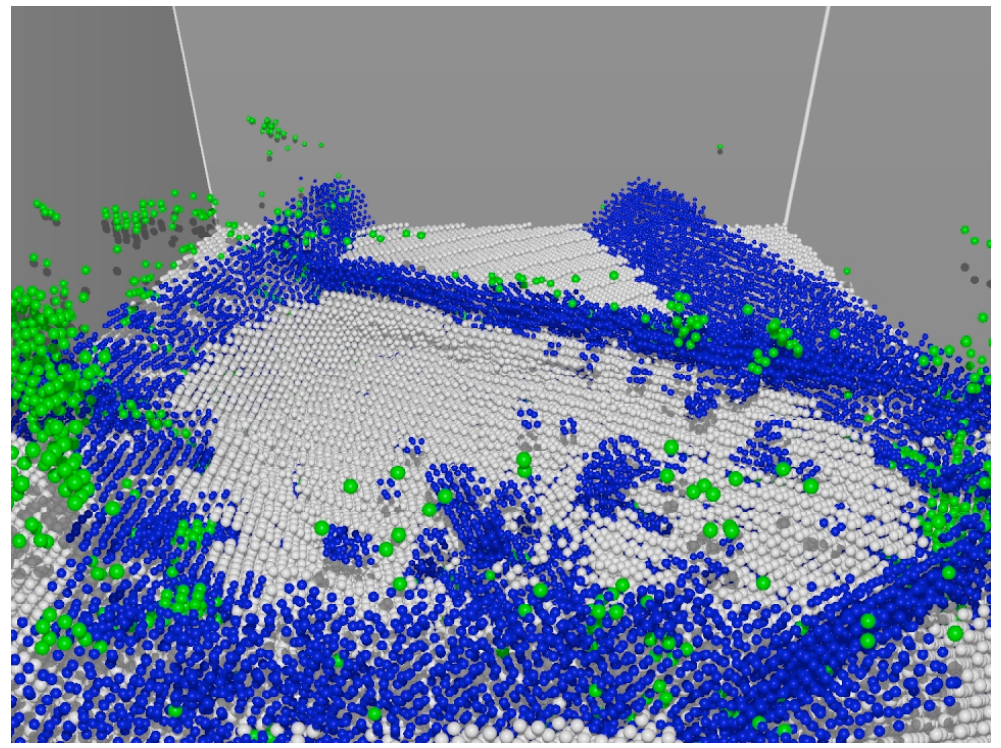

(c)

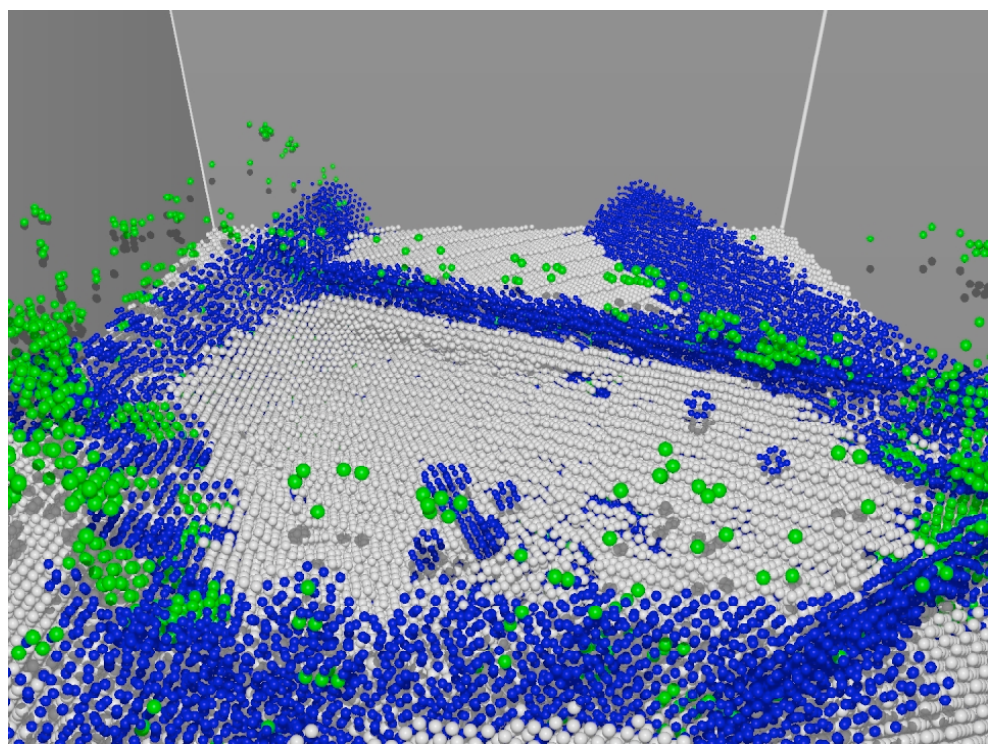

(d) 
Figure 3(a-b): Split-representations of the $\mathrm{Cu}$ nanocrystal after a $10 \mathrm{keV}$ recoil initiation, with the cascade debris centered near the middle of a grain. Figure 3(a) shows the instantaneous cascade structure (blue mass) and cascade track (light-blue dendritic feature) associated with the path of atoms that have energies larger than $5 \mathrm{eV}$. Figure 3(a) is at 0.9 psec after recoil initiation. White, green and blue spheres correspond to fcc, hcp and disordered atoms, respectively. (See text for details). Figure 3(b) shows the nanocrystal at $83 \mathrm{psec}$, where the grain boundary has become warped and a faulted hcp structure has formed.

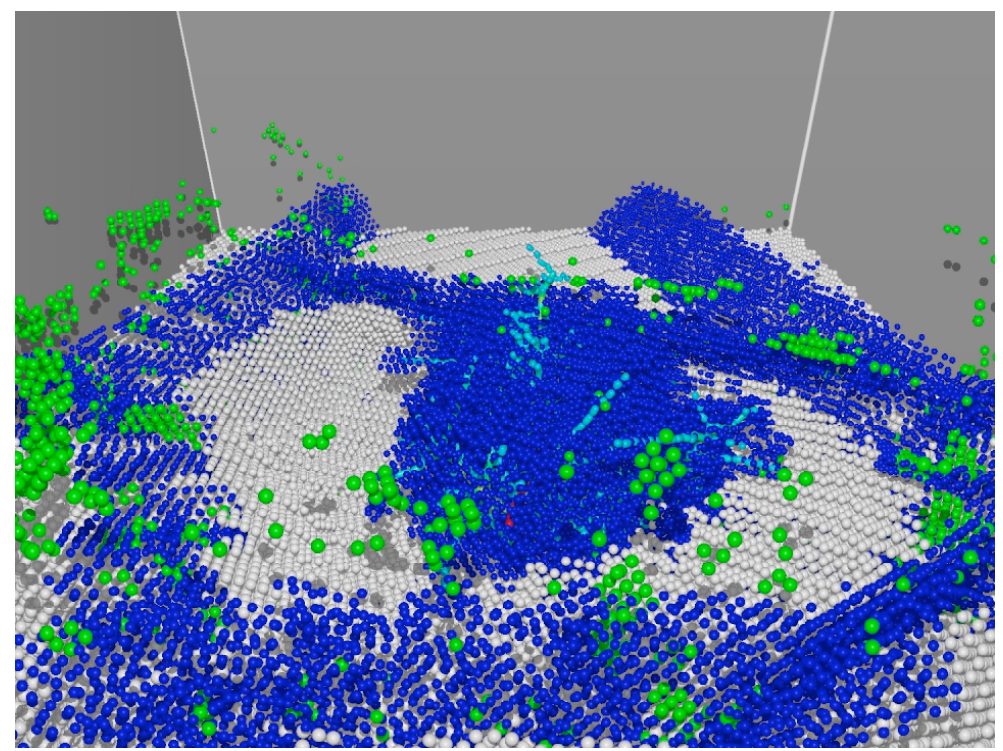

(a)

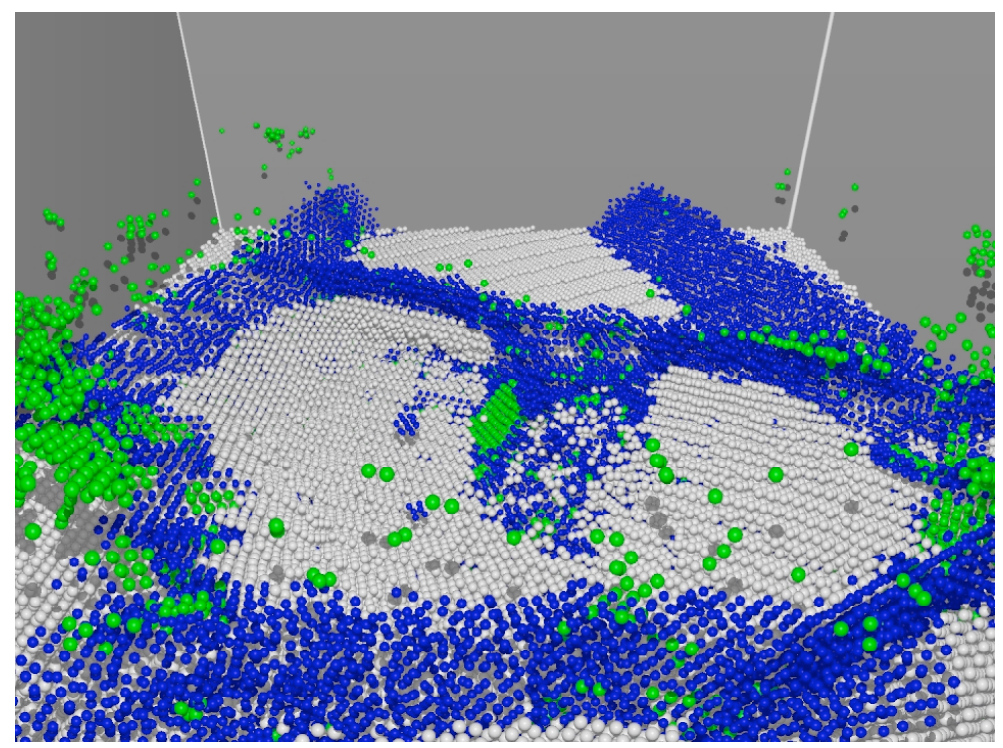

(b) 
Figure 4(a-b): Split-representations of the $\mathrm{Cu}$ nanocrystal after a $20 \mathrm{keV}$ recoil initiation. Figure 3(a) shows the instantaneous cascade structure (blue mass) and cascade track (light-blue dendritic feature) associated with the path of atoms that have energies larger than $5 \mathrm{eV}$. Figure 4(a) is at $1.2 \mathrm{psec}$ after recoil initiation. White, green and blue spheres correspond to fcc, hcp and disordered atoms, respectively. (See text for details). Figure 3(b) shows the nanocrystal at 19 psec, where a dislocation (green extended structure) has formed transiently from the cascade debris.

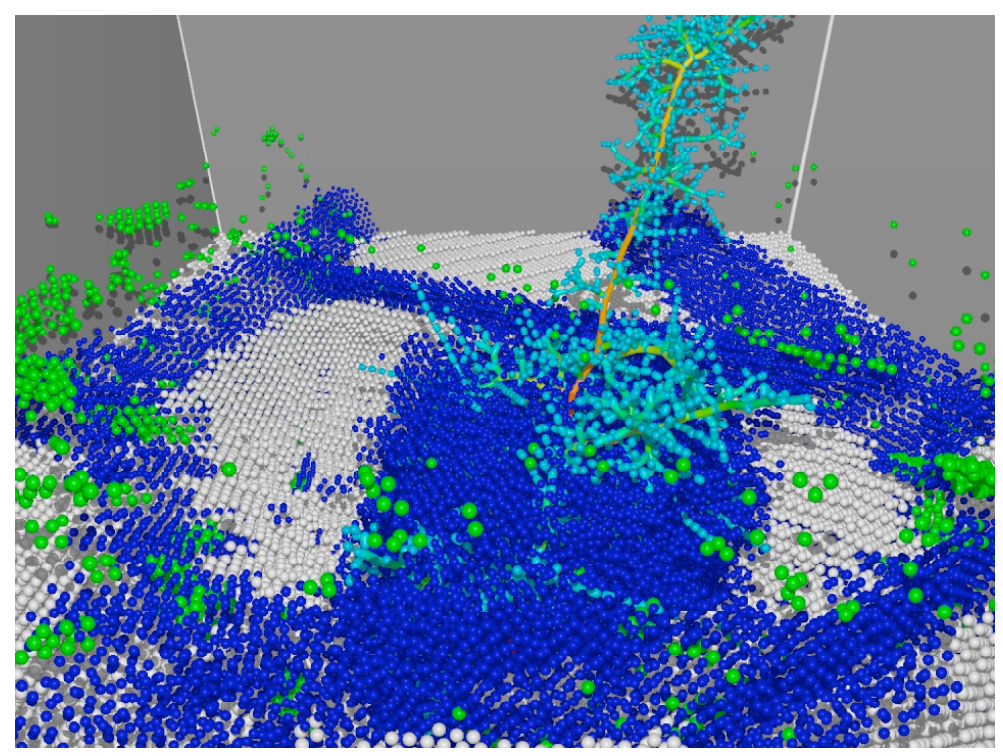

(a)

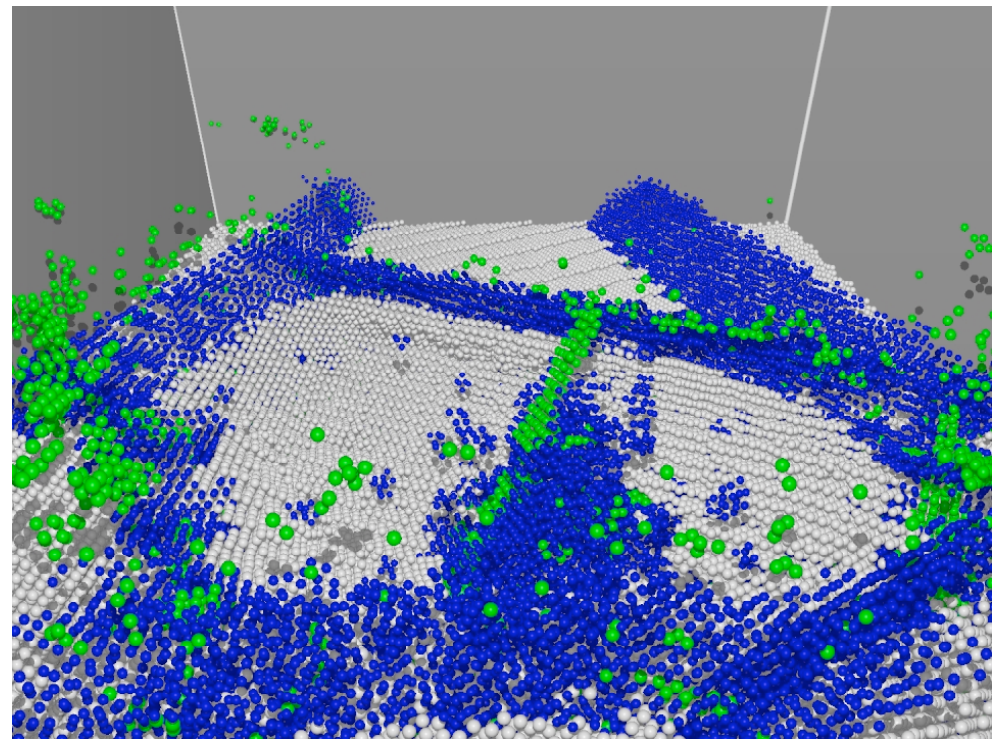

(b) 
Figure 4(c-d): Split-representations of the Cu nanocrystal after a $20 \mathrm{keV}$ recoil initiation. Figure 4(c) shows the nanocrystal at $24.7 \mathrm{psec}$, immediately after the dislocation in seen Figure 4(a) and the other cascade debris have collapsed into a cluster of truncated stacking fault tetrahedras. White, green and blue spheres correspond to fcc, hcp and disordered atoms, respectively. (See text for details). Figure 4(c) shows the nanocrystal at 227 psec, after the stacking fault tetrahedral complex has further collapsed into a single faulted loop structure that extends to the grain boundary.

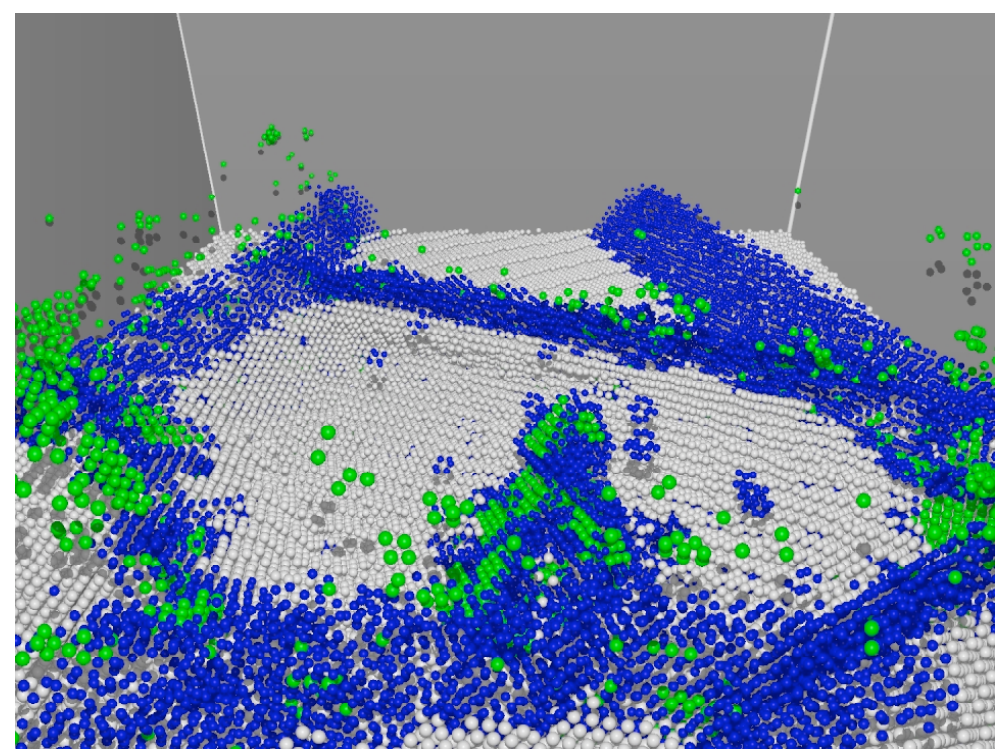

(c)

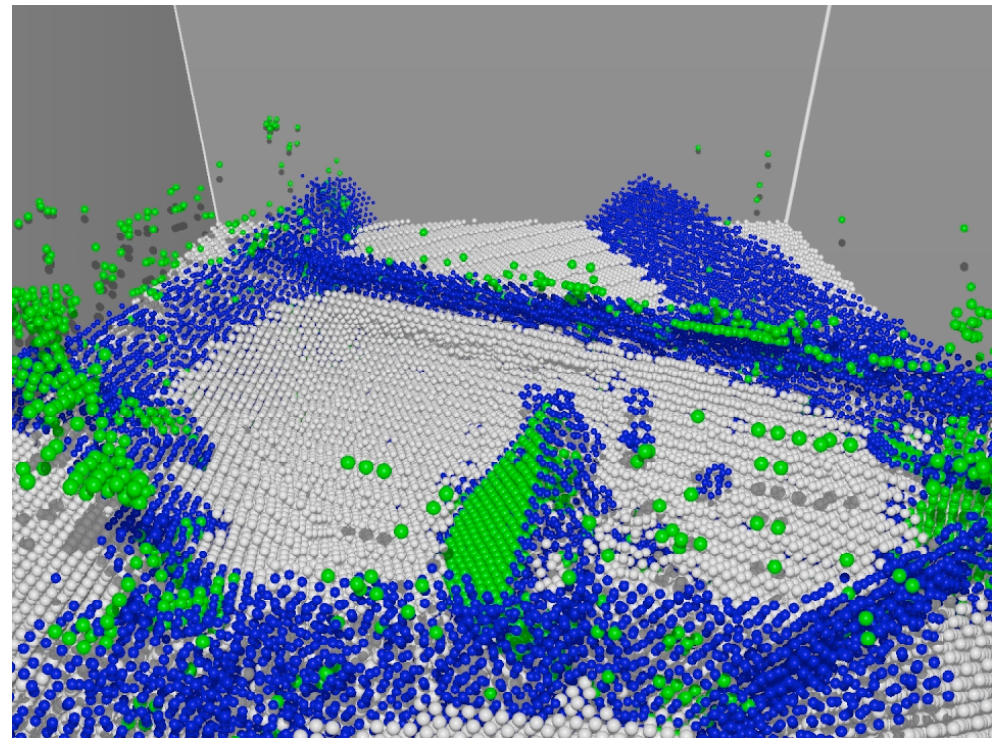

(d) 